\title{
Defending Shylock: Productive Work in Financial Markets
}

\author{
By Stephen R. C. Hicks, Ph.D.
}





\section{Defending Shylock: \\ Productive Work in Financial Markets}

\section{By Stephen R. C. Hicks}

Stephen Hicks, Ph.D., is Professor of Philosophy at Rockford College. His publications include Explaining Postmodernism: Skepticism and Socialism from Rousseau to Foucault (Scholargy, 2004), Nietzsche and the Nazis (Ockbam's Razor, 2010), Analyzing Arguments (W.W.Norton, 2011), and essays and reviews in academic and other publications.

\section{Introduction}

Legend has it that Aristotle Onassis had three rules of success. Mr. Onassis was, of course, the famed Greek shipping magnate, billionaire, and second husband of Jackie Kennedy. His advice was as follows:

1. Always borrow as much money as you can.

2. Always pay it back on time.

3. Always have a tan.

According to all who knew him, Mr. Onassis was extraordinarily successful on all three counts. If he were still alive, however, he would be at the center of at least two controversies. On the one hand, his advice about tanning would draw objections from those who disapprove of the health risk. On the other hand, his advice about borrowing money would put him in the line of fire of those who are suspicious of debt and the whole system of banks, venture capitalists, and financial markets that make debt increasingly easy to acquire.

Ambivalent attitudes about financial markets are as old as financial markets themselves. Plato, in The Republic (555e), condemns moneylenders. 
Jesus threw the money lenders out of the temple, on the grounds that they were defiling a holy place. Roman emperor Augustus, according to Suetonius' racy biography, was always especially displeased if he discovered any of his knights engaged in interest rate arbitrage (Suetonius, p. 76). Shakespeare, in Hamlet, has Polonius counsel his son "neither a lender nor a borrower be," and in The Merchant of Venice presents us with the image of the lender as a cunning Shylock hoping to extract his pound of flesh.

We are, in the twenty-first century, heir to all these views.

At same time, we are committed to financial markets. As business has grown in size and complexity, so have financial markets. Millions of us invest our money in pension funds, employee stock ownerships, and mutual funds. Thousands follow the stock market avocationally. And virtually everyone pays at least half-attention to the news telling us how the market did that day.

At times the tension between these two attitudes comes to a boil. The 1980s and 1990s were the most recent example.

In the late twentieth century, powerful forces were at work in financial markets. Major innovations were introduced, many institutions underwent radical restructurings, and as a result many fortunes were made. At the same time, the forces of suspicion and hostility to financial markets erupted. The 1980s were condemned as a "Decade of Greed." There were regular claims that the fortunes were being made by a few at the expense of the many, and that the power brokers of Wall Street were endangering the economic health of the nation just to grab a quick buck.

It is always hard to get an accurate perspective in the middle of revolutionary changes, but by the 2000 s sober assessments could be made about the net value of the changes-and the news was good.

\section{Good news about the late twentieth century}

Four events stand out in the financial history of 1970s, 80s, and 90s: (1) the introduction of futures contracts on non-agricultural commodities, (2) 
computerization, (3) the development of the junk bond, and (4) the wave of leveraged buyouts. A few words about each.

(1) There was a huge expansion in futures contracts on non-agricultural commodities. The late 1970 s and early 1980 s were a period of great volatility in interest rates and currency exchange rates, and that volatility spurred the development of new kinds of futures. Businesses affected by changes in the interest rate-for example, just about all of them - and businesses that utilize foreign exchange - for example, any business involved in import or exportwere facing a highly uncertain future. Just as traditional futures and options gave farmers and farm product consumers risk reduction and stability in the face of changing agricultural conditions, futures contracts for non-agricultural commodities were introduced to allow a wide range of businesses risk reduction and stability for their commodities. And so there has been incredible growth in futures markets.

For example, oil and gas fuels were traditionally subject to wild market fluctuations. Yet airlines, shipping companies, home heating delivery companies, major oil and gas companies need to make long-term plans. But how can you make long term plans when you don't have a clue what the price of fuel will be next month, let alone next year? Futures and options make this possible. A sign of their efficiency is that at just one exchange, the New York Mercantile Exchange, heating oil futures were introduced in 1978 and by 1990 over 35 million energy futures and option contracts were traded.

(2) Computerization also had a major impact on Wall Street. At the basic level, it increased the speed and ease with which trade orders can be executed, and so led to a reduction of trading costs. It also allowed traders to react more quickly to good and bad news, thus increasing the market's efficiency. And computers made possible more sophisticated analyses of market situations, giving traders more information upon which to base their decisions.

Computerization developed hand in hand with the increasing internationalization of financial markets. This meant that more capital became available more quickly from more sources. Internationalization also provided a check on government. As capital markets became more international, governments became less insulated from the effects of their domestic fiscal 
policies, and so had to become more cautious in implementing policies, knowing that capital markets in Tokyo and Zurich would punish them instantly for economically destructive policies.

(3) A third major event, the wave of leveraged buyouts, received much more publicity. Buyouts usually occur if someone recognizes that there is a gap between the value of assets as currently deployed and the expected higher value of those assets if redeployed. The redeployment of assets in the 1980s, however, was often painful: Many cases involved breakups of large divisions, parts of which were sold or shut down, meaning many individuals had to find new jobs.

Was all of this restructuring valuable? Yes. While some LBOs failed, it became clear that the net gain to the economy from the restructuring was huge-well over half a trillion dollars. Shareholders from whom the takeover company purchased shares averaged "about 30 to 50 percent over pre-offer prices.” Here I rely on a widely cited study by Harvard University's Michael Jensen:

the most careful academic research strongly suggests that takeovers-along with leveraged restructurings prompted by the threat of takeover-have generated large gains for shareholders and for the economy as a whole. My estimates indicate that over the 14-year period from 1976 to 1990, the $\$ 1.8$ trillion of corporate control transactions-that is, mergers, tender offers, divestitures, and $\mathrm{LBOs}$ - created over $\$ 650$ billion in value for selling-firm shareholders.

Compared to this enormous gain, Jensen estimated that losses to bondholders and banks did not exceed $\$ 50$ billion (in Jarrell 608-9).

However, what was really radical about LBOs was who was doing them. Instead of large companies taking over smaller companies, the newstyle buyouts were often larger companies being taken over by relatively small organizations. But small organizations do not have the assets on hand to take over large organizations, which means they have to go into debt, usually bigtime debt, to do so. Hence, leveraged buyouts. But to acquire leverage of this 
sort required creative new financing techniques, and this brings us to a fourth major event: the rise of the junk bond.

(4) Junk bonds made possible the scale of leveraged buyouts, and in large part the controversy surrounding junk bonds was a spillover from the controversy surrounding LBOs. So-called junk bonds arise from the fact that while there are roughly 23,000 companies with sales over $\$ 35$ million a year, only $5 \%$ can issue bonds that are rated investment grade. This means that in order to raise capital, 95\% (or about 22,000) of the companies have to issue non-investment grade bonds, go to banks or insurance companies for higher interest loans, or issue shares. Prior to pioneers like Michael Milken, there was no significant market for non-investment grade bonds; such bonds were considered junk. Milken and a few others essentially created that market. These bonds paid a higher rate of return in compensation for higher risk, thus satisfying investors, and they made it easier for most companies to raise capital.

While controversial, the vast majority of high-yield bonds, as Milken liked to call them, were solid investments. In 1987, "the average high yield company had 4000 employees, had been in business for thirty-six years, and had over $\$ 1$ billion in assets" (Bailey 51). And once tempers cooled off and the data came in, reports of research on junk-bond-or high-yield-companies showed that they in fact did better overall than other companies.

$[\mathrm{H}]$ igh-yield firms increased employment at an average annual rate of 6.7 percent, compared with 1.4 percent for industry in general, from 1980 to 1987. High-yield firms also outperformed their industrial counterparts in productivity. In output per hour of labor, industries with higher utilization of high-yield securities were more productive. In sales per employee, high yield firms averaged 3.2 percent growth annually,compared with an industrial average of 2.4 percent. The total invested capital of high yield firms grew at an average annual rate of 12.4 percent, compared with 9.9 percent for industry in general. New capital expenditures for property and plant equipment grew more than three times as fast among high-yield firms as they did for industry in general (10.6 percent versus 3.8 percent) (Yago 589-90). 


\section{Criticisms of financial markets}

But while all of this good stuff was going on, the dominant tone in the press, in popular culture, and to a large extent in the circle of professional commentators on financial matters was one of fear, suspicion, and even hostility. In some cases the negative reactions focused on leveraged buyouts or junk bonds, but the criticisms were the same criticisms that have been made against financial markets since financial markets began.

Consider three samples from professional intellectuals. First is former university president and holder of an endowed chair of ethics, Clarence Walton: "Complicating matters is the fact that these paper entrepreneurs from banking, accounting and law produce little or nothing of tangible use." And: "Investment bankers are slicing, dicing, chopping and reassembling American business and thereby accelerating the decline of U.S. competitiveness" (Walton 223).

Perhaps we would expect less insight into the nature of business from a professor of ethics, but here is from James Brock, a professor of business:

But they [the advocates of junk bonds] seem to have lost sight of the crucial distinction between productive capitalism and speculative capitalism. One expands what Adam Smith called the real wealth of a nation; the other merely redistributes existing wealth. One builds factories; the other redistributes ownership of existing plants. One gives birth to new goods, services, and production techniques; the other merely rearranges control over them. One contributes to economic growth and productive job creation; the other is a destructive zero-sum game (Brock 234).

And here is financial historian Dana Thomas:

The 1980s have experienced ... sabotagings of Wall Street's legitimate function, as speculators through dizzily leveraged buyouts fueled by junk-bond financing and insider trading manipulations have been pushing paper money around in a frenzied numbers game that has added nothing to America's industrial muscle (Thomas 347). 
The rhetoric also crops up in popular culture. Here are two prominent examples from the times. The first is from Michael Crichton's Rising Sun:

But all the kids want to dress like Charlie Sheen and make a million dollars before they're twenty-eight. The only way you can make that kind of money is in law, investment banking, Wall Street. Places where the game is paper profits, something for nothing.

The second is from the charming movie "Pretty Woman": Julia Roberts plays a prostitute who becomes romantically involved with a corporate raider played by Richard Gere. At one point Richard Gere is trying to explain what he does for a living, and the scriptwriter doesn't allow him to do a very good job of it. The prostitute cuts in during his explanation, saying, "So, you don't actually make anything." The corporate raider is forced to say that he does not. At which point the prostitute cleverly points out, "So you and I are really the same: we both screw people for money."

The primary charge in each case is that financial types do no productive work. They shuffle paper, they chop and slice, they rearrange a bit. But they do not create anything of value. The secondary charge follows: Even though they do no productive work, somehow they end up with a pile of money. It follows that they must have manipulated it away from honest working people-they got something for nothing, which means that somebody got screwed. Financial markets, it seems, are zero-sum games in which the parasitic win.

These claims and the moral outrage that goes with them are widespread, but they do not fit the historical facts. And so the questions naturally arise: What do people in financial markets do? Are they doing productive work? If so, what is the nature of it? What justifies their six, seven, and eight figure salaries and profit margins?

\section{Productive work in financial markets}

Markets do three major things: They allocate capital, provide risk reduction, and increase the efficiency of the markets themselves. In performing each of these general functions, markets have individuals performing specific functions. 
To allocate capital they need individuals to provide the capital (investors), individuals to make allocation decisions (analysts, fund managers, bankers), and individuals to bring together the investors and the users of capital (brokers, exchange managers). Arbitrageurs improve the efficiency of markets by increasing liquidity and the amount of information available to the market, and by keeping markets in sync with each other. Markets provide risk reduction through the selling and buying of futures and derivatives; this gives rise to the functions of those who manage the exchanges and speculators who increase liquidity and the sum total of information available to the market.

Performing each of these functions takes work: Where financial professionals earn their money is in what they do before the capital is actually allocated, before the risk reduction is provided, or before a measure is introduced to make the market function more efficiently. They think.

The need for thinking is not hard to see here. Unless one is simply gambling, the decision to allocate capital efficiently requires discrimination between enterprises that are more likely to be productive and those that are not. To make sound judgments about enterprises requires information. So the allocation of capital is a result of a process that begins with gathering information, evaluating that information, making judgments about relative productivity, and thereby deciding how to allocate one's capital. It is for this work that financial professionals earn their money. Part of the profit financial professionals earn is for the speed and accuracy of their information gathering and for the speed and soundness of their judgment. To the extent a financial professional can more accurately and more quickly allocate capital, he creates value. And to the extent someone inaccurately or slowly allocates capital, he wastes opportunities or actual capital.

Wall Street is, therefore, both a capital and an information clearinghouse. In financial markets, as in the rest of life, information is power and ignorance is death. Human beings survive by reason, and reason survives on the efficient flow of information. The principle is the same whether in life as a whole or in the sub-area of life we call the stock market.

Financial professionals, accordingly-whether investors in stocks or bonds, arbitrageurs, short sellers, and so on-get paid for thinking, for 
intellectual work. They are paid for the accuracy and speed of their allocation decisions.

While this point is not hard to grasp, it is exactly what the cruder criticisms of financial markets miss. Many will dismiss the whole of Wall Street as "gambling for paper profits." Here the obstacle for the critics seems to be the abstractness of the intellectual work done in financial markets. One cannot see intellectual work going on. One can see a farmer picking tomatoes, but grasping the nature of intellectual work requires abstraction.

The "paper profits" criticism misses two things. It misses the value of paper money, i.e., its ability to represent wealth abstractly. And, consequently, it misses the value of those who make the allocation of money more efficient. Understanding the productive work done by those who work with money requires that one ascend at least two levels of abstraction: One first must understand the function of money, and then one must understand the function of those who make the allocation of money more efficient. This many critics seem unwilling to do. And since they don't understand the work that is being done, it looks like gambling to them. But any skilled financial professionals would say what Andrew Carnegie said of his success in the steel business: "I am sure that any competent judge would be surprised how little I ever risked."

The unwillingness to ascend to abstractions sometimes results from a prejudice against intellectual work, in the form of an implicit labor theory of value. The labor theory of value holds that only physical labor is productive and that thinking is a more or less useless byproduct.

Consider the criticism that those who work in financial markets are "parasites." The "parasites" criticism is addressed by anyone closer to the actual physical labor to anyone further from the actual physical labor. For example, factory laborers will sometimes call their foremen parasites, pointing out that the foremen aren't actually operating machines but are merely standing around sipping coffee and telling other people what to do. Both laborers and foremen may call their managers parasites, pointing out that the managers make big bucks but aren't even on the factory floor-the managers are merely shuffling paper in their air-conditioned offices. Laborers, foremen, and managers will sometimes call the stockholders parasites: the stockholders are getting money 
but they aren't actually running the company. And so on. Stock index speculators are sometimes called parasites because they aren't actually investing in a company - they're only betting on whether a given index will rise or fall. In each case, the criticism is directed at the person further away from the factory floor, and in each case the criticism misses the productive power of abstractions.

Everyone from the laborer to stock index speculator is making allocation decisions. The difference is only in the scope of the allocation decision and the abstractness of the information that goes into the allocation decision. The laborer must decide how to allocate his time on a given project. The foreman must decide how to allocate his team of laborers. The office managers must decide how to allocate the entire resources of the company. The owner of stock must, before he buys, decide whether this entire company or that entire company is more productive. And the speculator in stock indexes must decide whether all of the companies in the index are, cumulatively, going to be more productive or less productive. As we move from laborer to index speculator, the scope of resource allocation decision increases, as does the amount of information that must be integrated before the decision is made. And so the importance of abstract thinking skills increases.

Broad, abstract thinking creates wealth. The foreman who, from his broader perspective than that of the laborer, sees a way to redeploy his team of laborers that is more efficient-is a creator of wealth. The company manager who, drawing on information from different parts of the company, is able to see a way to redeploy the company's assets more efficiently-is a creator of wealth. The stock index speculator who, integrating political and economic information from all over the world, sends a signal to the market to redeploy capital - is a creator of wealth. At each level of analysis, the point is the same: information within a certain scope must be integrated, and the person making decisions at that level creates wealth to the extent that he integrates that information correctly and then acts appropriately. And so it is appropriate that individuals are compensated in accordance with the scope and scale of the resource allocation decisions that they make. Intellectual workers earn their money.

That is the easy — and in some ways the least useful—part of this essay. 
The reason is that, in my experience, when I launch into an explanation of how markets work and isn't it wonderful how productive they are, I am almost always confronted with the Glazed Eyes Phenomenon. There is nothing like information to dispel suspicions, but for certain types of suspicions about financial markets, information about their productivity and efficiency is not especially relevant.

\section{The economic arguments do not address the general animus}

The hostility many have for financial markets has deeper roots than a simple lack of understanding of what they do. By analogy, imagine talking to a leftist about the power and effectiveness of the Central Intelligence Agency. Or imagine explaining to a Christian Scientist the skill and efficiency of various surgical procedures. Or imagine trying to explain the effectiveness of pesticides to the type of environmentalist who is certain that the chemical industry is upsetting the delicate balance of nature.

In each case, you are talking to someone who is committed to a wider framework within which those particulars are assigned little importance. The leftist knows that the CIA is evil, just as the Christian Scientist knows that secular medicine is useless, just as the doomster environmentalist knows that pesticides cause cancer. So the particular facts make no impact. For the same reason that explaining the economic efficiency of capitalism does little to lessen moral hostility to it, explaining the abstract productive work done by financiers does very little to lessen hostility to Wall Street.

Consider the following extraordinarily honest statement by financial writer Michael Thomas: "You don't have to know what a junk bond is to become infuriated by one" (in Bailey 274). Thomas is saying that he has a background set of moral views that tell him ahead of time whether a new capitalist tool is good or bad. "You don't have to know what a junk bond is to become infuriated by one" - it's capitalism, and not only that, it's Wall Street, and not only that, it's some fancy-schmancy new device that only the big boys understand and the rest of us are going to have to pay for.

The root problem is that many people are predisposed to believe the worst about business and especially about Wall Street. The widespread suspicion 
about the moral standing of business in general has little to do with a lack of understanding of the mechanics of Wall Street. The lack of understanding only intensifies suspicions that are already there. So it is the moral framework that predisposes people to be suspicious of Wall Street that we must address.

\section{Roots of the general animus}

The root of the problem is the status that self interest has in the eyes of most moralists. The dominant moral view in our culture is that self interest is, at best, an amoral motive. At worst, self interest is seen as immoral because it means putting yourself first and others second, which to many means that one is willing to harm others to get ahead. Self interest, accordingly, is seen as dangerous. By contrast, not being willing to harm others is taken to mean seeing yourself as of less importance, i.e., being selfless. Selflessness is thus seen as essential for social harmony, while self interest is seen as a destructive, antisocial force.

While this distrust of self interest and praise for altruism is institutionalized in our culture's intellectual circles, outside those circles we have a greater respect for self interest. We encourage people to seek the American Dream and to be, as the Army used to put it, all you can be. But mixed in with this is a trickle-down effect from the intellectuals in the form of a mild suspicion of self interest and a respect for altruism.

But when the stakes become large, as they do in politics and in big business, suspicions of self interest come to the fore. Most intellectuals' consistent distrust of self interest and the average citizen's ambivalence about self interest converge upon large-scale manifestations of self interest-corporations, financial markets, or the social system within which these flourish best, capitalism.

Each of these institutions puts self interest at the core of social relations. It follows that nothing any of those institutions does will ever gather moral praise from those intellectuals who are convinced that self interest is amoral. That some good social consequences can come from self interest will be seen as nice (although a little paradoxical) but not as morally relevant. What is morally relevant is the motive, and their motive is the profit motive-and so no moral credit will be given. 
Capitalism, business, and financial markets in particular, are thus placed by our culture's dominant morality in a general evaluative category-the to-be-tolerated but still suspicious actions of self-interested agents.

\section{Shylock}

Consider the case of Shylock, one of the most powerful symbols of human evil in literature. Shylock is a financier. He is also a Jew. And on both counts he is beyond the pale as defined by Christian ethics, the dominant ethic in both Shakespeare's time and ours. Jews are allowed by their religion to charge interest, while Christians traditionally were not. Jesus, we recall, threw the moneylenders out of the temple. This moral condemnation of the business of finance is the heart of the matter in Shakespeare's The Merchant of Venice. The ethical difference is partly why Antonio has a generalized disgust for Jews, which he focuses on Shylock in the form of insults and spit. Not surprisingly, this causes Shylock to feel resentment.

But that is not the real problem. Shylock really hates Antonio because Antonio lends out money without charging interest. Antonio's doing so has the effect of driving down the interest rate, thus hurting Shylock's business. So Shylock also feels resentment and a desire for revenge on that account. Consequently, when the opportunity arises, he gets Antonio to accept the notorious pound-of-flesh agreement. But he does not really want Antonio to pay back the money-he would much rather that Antonio forfeit so he can cut out his heart.

Shylock is thus a brutal, dehumanized individual. But the way Shakespeare has set things up, it is the business of finance that is at the heart of man's inhumanity to man. Antonio despises Shylock because he is one of those Jews who immorally charge interest. And Shylock hates Antonio because he is hurting his business. And here the controversy among literary critics about Shakespeare's intent-whether to express his own views about Jews and moneylenders, or simply to reflect current attitudes, or to provide comic relief, or to expose anti-Semitism as an evil-does not matter. Either Shakespeare agreed or disagreed with the majority culture about Shylock, and in either case the dominant cultural position is that Shylock the moneylender is evil, and the dominant cultural position is that corrupt business is at the heart of it. 
The important point for our purposes is that the Shylock stereotype did not die with Shakespeare's generation. In the modern world, attitudes towards business are healthier, but every generation has individuals whom the media represent as Shylocks. Antipathy toward financial markets usually exists in vague form, directed toward impersonal, abstract institutions- "Wall Street." But it regularly becomes focused on individual human beings who serve as symbols of everything that is thought to be wrong with financial markets. In the late 1800s, the name might be Jay Gould. In the early 1900s, J. P. Morgan. In the late 1900s, Ivan Boesky or Michael Milken. In the early 2000s, Martha Stewart. The truth or falsity of the charges against these individuals is not the point here; in some cases, the charges seem true, in others wildly unjust. The issue is the function the names serve in attacks on Wall Street. The names evoke and serve as rallying cries for reactions that are usually incredibly out of proportion to the circumstances of the case. The individuals behind the names are all, deserving or not, seen as parasites, as evil, as deserving of whatever invective and spit can be directed to them. "He should," wrote columnist Donald Kaul of Michael Milken, "be tied by the ankles to the rear bumper of a pick up truck and taken on a slow tour of a long gravel road. Then his head should be put on a spike and taken around to the nation's most prestigious business schools as a lesson in ethics" (in Bailey 244).

Broad moral categorizations thus have a lot of power. Current moral theory and cultural belief, just as in Shakespeare's time, put financial markets in the amoral/immoral category and predispose people to expect that Shylocks run the financial markets. This categorization sets the overall framework within which everything that financial markets do is evaluated. So one can try with great eloquence to point out that the effects of financial markets are good—junk bonds have created wealth, LBOs have improved efficiency — but find that these effects are largely brushed off because the self-interested intent behind those effects is not seen as good.

So far we have two ingredients that explain the negative evaluation of financial markets: They are abstract and they are based on self interest.

A third ingredient must be added: Envy. People who work in financial markets often make a lot of money. For those who make less, that can be a bitter pill and evoke powerful feelings of resentment and envy. 
Consider again the case of Michael Milken. During his trial, Milken's lawyers tried to keep quiet the fact that during one wildly-successful year Milken earned over $\$ 500$ million. They tried to keep it quiet because they knew what public opinion would do to them if it got out. They were right.

One hostile financial writer named Benjamin Stein confessed in print to feeling "red surges of envy" upon hearing of Milken's earnings (in Bailey 215). Imagine what red surges of envy must feel like. Then imagine what it means for a professional financial writer to announce publicly his envy as part of his hostility. The best explanation is that Stein felt justified in his feelingsthat he believes that since the big boys in Wall Street are amoral and immoral players within a morally corrupt system, envy is both an understandable and legitimate reaction. Stein is thus in a long intellectual tradition, from JeanJacques Rousseau to John Rawls, that feels that envy is a powerful social force that is sometimes legitimate and that must be appeased.

I expect that this extreme of envy and Shylock stereotypes defines a limit on a spectrum of degrees of hostility toward financial markets. But this spectrum defines the cultural atmosphere in which those of us who think that financial markets are good have to argue. In this atmosphere,careful explanations of the value that arbitrageurs create are important, but they will not get us very far. What we need is something that addresses the moral standing of financial markets. What we need is a challenge to the culture that can produce Shylock as the stereotype of the financier and reincarnate him every generation or so as J. P. Morgan or Michael Milken. What must be argued is that financial markets are not to be tolerated but rather venerated as institutions within which some of the noblest work humans can do is performed. This requires a new moral framework within which to place financial markets.

\section{The nobility of financial markets}

Here I turn to Ayn Rand's alternative to the traditional moral frameworks (Rand 1957, 1963). The key element of any business ethic is its moral evaluation of profit. Financial markets institutionalize the profit motive, and it is suspicion of the profit motive that lies at the heart of attacks on financial markets. This, historically, is a consequence of the fact that virtually all traditional moralities hold that profit-seeking is at best amoral. Ayn Rand's 
philosophy of Objectivism is unique among moral philosophies in arguing that the profit motive is a profoundly moral motive. The profit motive is the expression of rational self-interest. It is, in broadest terms, the motive to better one's life. It is, in economic terms, the motive to achieve a net return on one's investment.

If life is individual, as Objectivism argues it is, then each individual's life is his highest value; his life belongs to him. The corollary of this is that the achieving of each individual's highest value is each individual's responsibility. We are ends in ourselves and the primary means to our ends. Individuals are moral, accordingly, to the extent they take responsibility for their own lives and take steps to achieve their happiness. We derive great joys and benefits from social life, but the social is a means to an end-the benefit of the individuals involved.

Gain is not a luxury but is built into the objective requirements of life. Gain is a measure of growth. In biological terms, to stay alive, an individual must consume at least as much energy as he expended in producing the value to be consumed; and to grow, an individual must consume more energy than he expended in producing the value. In economic terms, to succeed in business he must achieve a net return on his investment, i.e., he must make a monetary profit. In emotional terms, to achieve happiness he must find that the joys of doing and succeeding outweigh the frustrations.

If the measure of the good life is the extent to which an individual flourishes psychologically and existentially, then gain is one measure of the good life. It follows, then, that an individual motivated by gain is a moral individual, and social institutions that maximize individuals' abilities to gain are moral institutions.

Business is then one application. Business is about production and trade. Production is a consequence of individuals' taking responsibility for their lives and exercising rational judgment about their needs and how to fulfill them. Trade is a consequence of productive individuals' willingness to interact cooperatively to mutual benefit. These principles-responsibility, rationality, cooperation - are core principles in any healthy moral system, and they form the core principles of the business world. In business the moral individual is the producer - the individual who is an end in himself, independent in thought 
and action. Moral social relations are voluntary interactions to mutual benefit by productive individuals. Businesses and consumers, employers and employees are self-responsible ends in themselves who trade to mutual advantage. Neither is fundamentally in conflict with another, and neither is to be sacrificed to the other. Given these broad non-conflictual principles, differences over details are sorted out by negotiation. Governments enforce the non-conflictual principles and protect the negotiated contracts.

If we think of virtuous individuals as individuals with the characteristics necessary for achieving the good life, then virtuous institutions will be those that have the characteristics necessary to enable individuals to gain, i.e., to achieve some part of the good life.

Financial markets, accordingly, must be recognized as highly moral human institutions. If we highlight six virtues of institutions, we will find financial markets achieve all six.

- Moral institutions encourage people to achieve the values necessary for happiness. Financial markets do this: they institutionalize the profit motive.

- Ideal institutions successfully provide a vehicle for individuals to create those values. Financial markets have been enormously successful in creating wealth.

- Ideal institutions require that the exercise of virtues-rationality, honesty, integrity, justice-be a condition of success. Success in financial markets does require virtue: one cannot function there without applying one's intelligence fully, consistently, and without maintaining one's courage and confidence under sometimes enormous pressure.

- Ideal institutions reward individuals to the extent - and only to the extent-that they create value. In financial markets individuals are rewarded by profit only to the extent they make accurate allocation decisions. Only success is rewarded, never failure. 
- Ideal institutions permit only voluntary interactions among participants. This is true of financial markets: a trade is made only if buyer and seller agree.

- Finally, ideal institutions institutionalize checks on abuses and mistakes. This too is true of financial markets: instruments of accountability, improvement, and conflict resolution are constantly evolving and improving.

Judged by these criteria, financial markets are highly virtuous institutions. Obviously this is not to say that everyone who works in financial markets is a moral hero or that mistakes and abuses never happen. But it is to say that injustices are aberrations in the system and that the system is designed to help us be that best we can be. Financial markets do create value, and they do so by encouraging in us the core of moral excellence. We cannot ask more of any institution.

\section{References}

Bailey, Fenton. 1992. Fall from Grace: The Untold Story of Michael Milken. New York: Birch Lane Press.

Brock, James W. 1993. “Junking Corporate America.” Critical Review 7:2-3, 225-236.

Jarrell, Gregg. 1993. “Takeovers and Leveraged Buyouts.” In David R. Henderson, ed., The Fortune Encyclopedia of Economics. New York: Time Warner.

Rand, Ayn. 1957. Atlas Shrugged. New York: Random House.

Rand, Ayn. 1963. The Virtue of Selfishness. New York: Signet. 
Suetonius. 1957. The Twelve Caesars, trans. Robert Graves. Penguin.

Walton, Clarence. 1989. In Oliver F. Williams, Frank K. Reilly, \& John W. Houck, eds. Ethics \& the Investment Industry. Rowman \& Littlefield.

Thomas, Dana L. 1989. The Plungers and the Peacocks. New York: William Morrow.

Yago, Glenn Yago. 1993. “Junk Bonds.”In David R. Henderson, ed., The Fortune Encyclopedia of Economics. New York: Time Warner.

(C) Stephen R. C. Hicks. This essay is based on a talk originally delivered at a conference of the Institute for Objectivist Studies in New York, New York in 1995 and published in 1998. Reprinted with permission by The Center for Ethics and Entrepreneurship, 2010. 
